\title{
Photoresist Removal Using H Radicals Generated by Iridium Hot-Wire Catalyst
}

\author{
Masashi Yamamoto, ${ }^{1}$ Shiro Nagaoka, ${ }^{2}$ Hironobu Umemoto, ${ }^{3}$ Keisuke Ohdaira, ${ }^{4}$ \\ Takashi Nishiyama, ${ }^{5}$ and Hideo Horibe ${ }^{5}$ \\ ${ }^{1}$ Department of Electrical and Computer Engineering, National Institute of Technology, Kagawa College, 355 Chokushi-cho, \\ Takamatsu, Kagawa 761-8058, Japan \\ ${ }^{2}$ Department of Electronic Systems Engineering, National Institute of Technology, Kagawa College, 551 Kohda, Takuma-cho, \\ Mitoyo, Kagawa 769-1192, Japan \\ ${ }^{3}$ Graduate School of Integrated Science and Technology, Shizuoka University, 3-5-1 Johoku, Naka-ku, Hamamatsu 432-8561, Japan \\ ${ }^{4} J a p a n$ Advanced Institute of Science and Technology, 1-1 Asahidai, Nomi, Ishikawa 923-1292, Japan \\ ${ }^{5}$ Graduate School of Engineering, Osaka City University, 3-3-138 Sugimoto, Sumiyoshi, Osaka 558-8585, Japan
}

Correspondence should be addressed to Masashi Yamamoto; m-yamamoto@t.kagawa-nct.ac.jp

Received 5 March 2017; Accepted 10 August 2017; Published 19 September 2017

Academic Editor: Antonio Facchetti

Copyright (c) 2017 Masashi Yamamoto et al. This is an open access article distributed under the Creative Commons Attribution License, which permits unrestricted use, distribution, and reproduction in any medium, provided the original work is properly cited.

We examined an environmentally friendly photoresist removal method using $\mathrm{H}$ radicals produced by decomposing hydrogen on a hot iridium catalyst. We examined the relationship between photoresist removal rate and its surface temperature using thin film interference and the removal properties using $\mathrm{H}$ radicals produced by the Ir catalyst. Decomposition behavior at polymer surface by radicals may be analyzed in further detail from the aspect of kinetics. Additionally, we investigated the oxygen addition effects on the removal rate. The photoresist removal rate increased with the oxygen additive amount and then decreased more gradually than in the case of using W filament. The increasing behavior was similar but there was a large difference between W and Ir catalyst in the decreasing behavior.

\section{Introduction}

A lithography process using photoresist is indispensable for fabricating current electronic devices. Roles of photoresists are to protect the substrate surfaces from the etching, the thin film deposition, and the ion-implantation. Photoresists have to be removed at the end of the process. In the removal of photoresist, there are some problems, such as the environmental impacts and the costs of the chemicals because hazardous chemicals are usually used for removal [13]. As one of the removal methods without the chemicals, the removal method by an ashing, in which photoresist was decomposed to oxide-carbon compounds by using the oxygen plasma [4-7], is used to remove photoresists in some cases. However, device performances may be destabilized by charged particles in the plasma. Instead of the ashing, photoresist removal methods not using the chemicals and plasma are desired in order to solve these problems.

Photoresist removal using $\mathrm{H}$ radicals, which have excellent reduction power, is one of the most effective methods to break the problems because this method is chemical- and plasma-free [8-13]. H radicals are generated by decomposing molecular hydrogen on metal hot-wire catalysts [14-16]. Photoresists are probably decomposed by $\mathrm{H}$ radicals into volatile hydrogenated products. However, one of the problems of this method is its low removal rate.

Some findings related to the use of $\mathrm{H}$ radicals generated on a tungsten hot-wire catalyst for the photoresist removal have already been reported [8-13]. In a previous study we achieved a best removal rate of $2.5 \mu \mathrm{m} / \mathrm{min}$ using $\mathrm{H}$ radicals by heating up the catalyst and the substrate [10], but there are limitations. The combination of $\mathrm{H}$ and other radicals is 
probably another effective choice for a breakthrough. We have examined the effects of oxygen addition under the presence of $\mathrm{H}$ radicals to produce $\mathrm{OH}$ radicals together with $\mathrm{H}$ radicals using the tungsten hot-wire catalyst $[17,18]$.

The removal rate increased with oxygen additive amount up to an optimal amount and then, however, decreased gradually. The decrease in the removal rate might be caused by the decrease in the production rate of $\mathrm{H}$ radicals caused by catalytic poisoning of the excessively added oxygen. Umemoto et al. have reported that the poisoning does not occur under the oxygen additive amount of less than $12 \%$ when using Ir filament [19]. On the other hand, there is no study about photoresist removal using $\mathrm{H}$ radicals produced by Ir hot-wire catalyst. In this paper, we would report the removal properties using $\mathrm{H}$ radicals produced by the $\mathrm{Ir}$ catalyst and the oxygen addition effects on the removal rate.

\section{Experimental Methods}

The experimental apparatus and the procedure were similar to those described elsewhere $[13,17,18]$. A cylindrical vacuum chamber made of stainless steel was used. The flow rate of hydrogen gas ( $\geq 99.99 \%$; Air Liquide Japan) was fixed at $100 \mathrm{sccm}$ using a mass flow controller (SEC-400MK2; STEC Inc.). The oxygen gas flow rate ( $\geq 99.5 \%$; Iwatani Sangyo Co. Ltd.) was varied between 0 and $10.0 \mathrm{sccm}$ using another mass flow controller (SEC-400MK3; STEC Inc.). In other words, the amount of oxygen addition, the flow rate ratios of $\mathrm{O}_{2}$ to $\mathrm{H}_{2}$, was varied between 0 and $10.0 \%$. Before supplying gases, the chamber was evacuated to $10^{-2} \mathrm{~Pa}$ using an oil-sealed rotary vacuum pump (D-330DK; Ulvac Inc.). The typical total pressure under processing, measured using a vacuum gauge (Baratoron 622A12TAE; MKS Instruments Inc.), was $20 \mathrm{~Pa}$. The substrate stage temperature was $260^{\circ} \mathrm{C}$.

A resistively heated iridium wire $(99.5 \%, 0.5 \mathrm{~mm}$ diameter, and $500 \mathrm{~mm}$ long, TANAKA HOLDINGS Co., Ltd.) was used as a hot-wire catalyst. This wire was coiled with 14 turns. The coil length and the diameter were $50 \mathrm{~mm}$ and $8 \mathrm{~mm}$, respectively. The distance between the catalyst and the substrate was $20 \mathrm{~mm}$. A DC power supply (EX-750L2; Takasago Ltd.) was used to heat the catalyst. The catalyst temperature was measured using a two-wavelength $(0.8$ and $1.05 \mu \mathrm{m})$ infrared radiation thermometer (ISR12-L0; Impac Electronic $\mathrm{GmbH}$ ) through a quartz window. The output power was adjusted to be between 80 and $165 \mathrm{~W}$, and the catalyst temperature was varied between 1200 and $1600^{\circ} \mathrm{C}$.

A positive-tone novolak photoresist (OFPR-800; Tokyo Ohka Kogyo Co. Ltd.) was used for this study. It was spincoated onto a p-type $\mathrm{Si}(100)$ wafer using a spin coater (K359 S-1; Kyowa Riken Co. Ltd.) at $2600 \mathrm{rpm}$ for $20 \mathrm{~s}$. The wafer surface was cleaned up with acetone-saturated cotton and then dried naturally at room temperature before spincoating. Then it was prebaked in an oven (CLO-2AH; Koyo Thermo Systems Co. Ltd.) at $100^{\circ} \mathrm{C}$ for $60 \mathrm{~s}$. The photoresist film thickness was about $1 \mu \mathrm{m}$, as measured using a surface texture measuring instrument (SURFCOM 480A; Tokyo Seimitsu Co. Ltd.). In order to examine the relationship between the removal rate and the baking temperature of

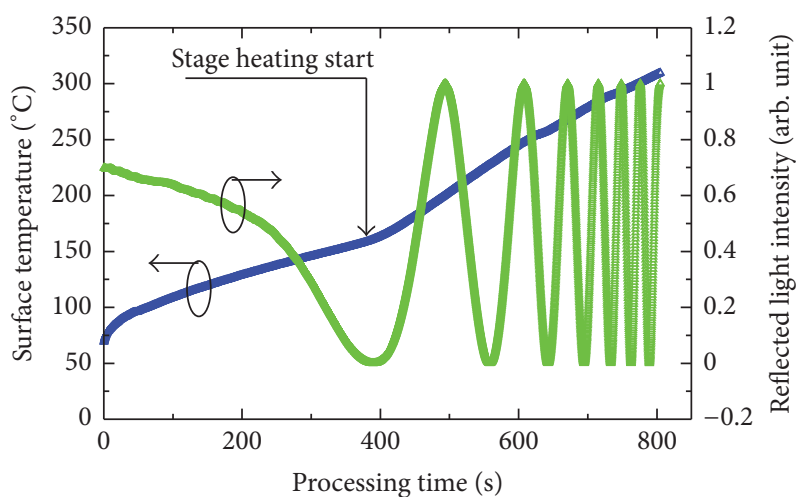

FIgURE 1: The reflected light intensity and the surface temperature as a function of processing time. The photoresist film was only prebaked at $100^{\circ} \mathrm{C}$ for $60 \mathrm{~s}$. The catalyst temperature was $1600^{\circ} \mathrm{C}$.

photoresist, we baked photoresist additionally at 150,200 , and $250^{\circ} \mathrm{C}$ for $10 \mathrm{~min}$, respectively, after prebaking.

The change in the film thickness during processing was monitored using an optical interferotype film thickness measurement system. The optical source ( $150 \mathrm{~mW}$; Civil Laser) wavelength was $520 \mathrm{~nm}$. A phototransistor (NJL7502 l; New Japan Radio Co. Ltd.) was used as a detector. The laser light entered the center of the stage. The incidence angle against the substrate surface plane was $76^{\circ}$. The phototransistor has its emitter connected to ground. Its collector was connected to $+5 \mathrm{~V} \mathrm{DC}$ through a pull-up resistor $(1 \mathrm{k} \Omega)$.

In order to examine the relationship between the removal rate and the surface temperature, we heated the substrate temperature from 20 to $300^{\circ} \mathrm{C}$. The substrate was also heated using thermal radiation from the hot catalyst. The temperatures of the substrate and its surface were measured using two K-type thermocouples. In surface temperature measurements, a small thermocouple (ST-56K-CC $0200 \mathrm{~N}-\mathrm{N}$; RKC Instrument Inc.) was used to avoid disturbing the measurements. The thermocouple was placed on the substrate surface, $5 \mathrm{~mm}$ distant from the stage center. The substrate temperature and the film thickness were measured simultaneously at an interval of $0.1 \mathrm{~s}$.

In the optical interferotype film thickness measurement, peaks and valleys of reflected light intensity can be observed alternately, corresponding to changes in the film thickness. The reflected light intensity becomes constant when the photoresists are removed completely in the laser-irradiated area. It is possible to ascertain the end point and the removal time. At the end point, the irradiation of radicals was stopped.

\section{Results and Discussions}

Figure 1 depicts the surface temperature and the normalized reflected light intensity as a function of processing time. Although the initial surface temperature was $20^{\circ} \mathrm{C}$, its temperature rose up to $69^{\circ} \mathrm{C}$ immediately as soon as heating the filament was started. We started to heat the substrate holder temperature at $380 \mathrm{~s}$ after irradiation. Then the surface temperature increased faster than before. The reflected light intensity becomes maximum and constant when the 
photoresists were completely removed. The reflected light intensity after $804.4 \mathrm{~s}$ is constant, so the laser-irradiated area of photoresist is removed completely.

In the thin film interference, the peaks and valleys of the reflected light intensity can be alternately observed due to the changes in film thickness. In this case, the photoresist film thickness change between the neighboring peak and the valley corresponds to about $77 \mathrm{~nm}$ [17]. The removal rate presumably increases when the surface temperature becomes hot, because the alternate cycles of the intensity decreased with increase in the surface temperature.

We can estimate the removal rate by the film thickness change at each peak-valley time interval, but the results lack details. We calculated the film thickness using the results of the intensity measurements to analyze the removal rate in a shorter time interval than the peak-valley time interval. The reflected light intensity $I$ detected by the photodetector is expressed by the following equation:

$$
I=\left(W_{1}^{2}+W_{2}^{2}\right)+2 W_{1} W_{2} \cos \left[2 \pi \frac{2 f \sin \theta_{\mathrm{PR}}}{\lambda / n}\right] .
$$

Here, $W_{1}$ is RMS value of a sinusoidal wave of the reflected light at photoresist film surface and $W_{2}$ is also the value at Siwafer surface. The film thickness $f$ is about $1 \mu \mathrm{m}, \theta_{\mathrm{PR}}\left(\cong 81^{\circ}\right)$ is the incidence angle in Si-wafer surface, and refractive index of the film $n$ is 1.66 .

Although $W_{2}$ is strictly relevant to the film thickness, the cosine function term of (1) is probably the most dominant as shown in Figure 1 because the reflected light intensity changed alternately and the absorption of the film may be negligible because the film is nearly transparent at $532 \mathrm{~nm}$ light. Therefore, we simplified (1) to the following equation by correcting the first term and normalizing the second term of the equation:

$$
I_{\text {normalized }} \propto \frac{1}{2}\left(1+\cos \left[2 \pi \frac{2 f \sin \theta_{\mathrm{PR}}}{\lambda / n}\right]\right) .
$$

We can measure the intensity $I$. The photoresist removal rate can be calculated from the film thickness change at each measurement period by using the results of $I$ measurements. Figure 2 depicts the removal rate as a function of surface temperature. The increase in removal rate at the surface temperature in the range $150-225^{\circ} \mathrm{C}$ is presumably induced by thermal shrinking of photoresist film [10]. The shrinking might be caused mainly by the volume loss due to volatilization of the solutions contained in the film. In order to clarify the influence of the shrinking on the removal rate, we also examined the film thick as a function of the surface temperature for the additionally baked substrates after prebaking. The baking temperatures are 150, 200, and $250^{\circ} \mathrm{C}$, respectively. The baking time is $10 \mathrm{~min}$. Consequently, we found that the shrinking on removal rate has little influence on the baking temperatures in excess of $200^{\circ} \mathrm{C}$.

Figure 3 depicts the removal rate as a function of the additional baking temperature for the surface temperature $\left(T_{\text {surf }}\right)$. We selected the surface temperature in excess of $250^{\circ} \mathrm{C}$ because the effect of the shrinking on the removal rate is presumably little, according to Figure 2. Removal

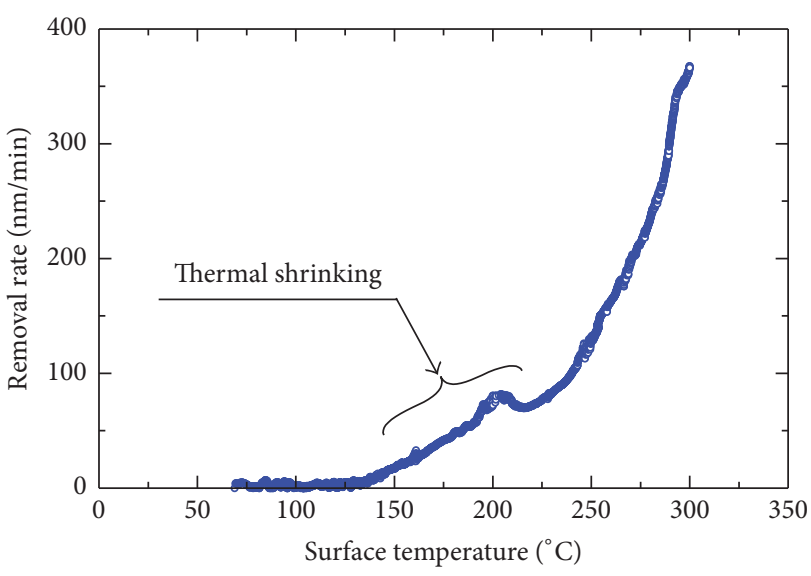

FIGURE 2: Removal rate calculated from the results of Figure 1 as a function of surface temperature.

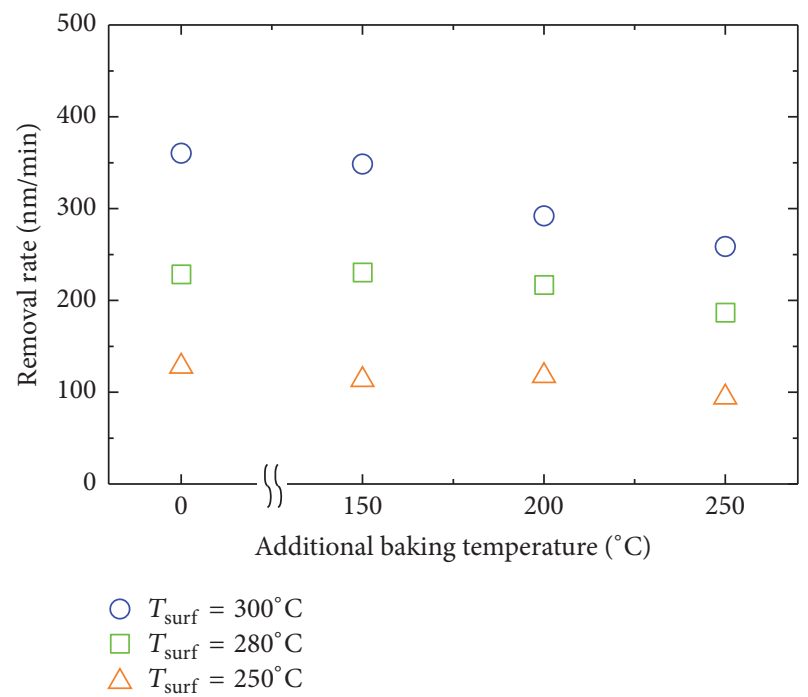

FIgURE 3: The removal rate as a function of the additional baking temperature when the surface temperatures were 250, 280, and $300^{\circ} \mathrm{C}$, respectively.

rate decreased with increase in the baking temperature. The decrease in removal rate might be caused by the hardening of polymer because the novolak resin is cross-linked by thermal curing.

Figure 4 depicts the removal rate as a function of the filament temperature when the surface temperatures are 250, 280 , and $300^{\circ} \mathrm{C}$, respectively. The removal rate increased with increase in the catalyst temperature at each surface temperature. The density of $\mathrm{H}$ radical increases exponentially with increasing the filament temperature $[16,19,20]$ and the removal rate also increases in proportion to the density [11]. Therefore, the increase in the removal rate is ascribed to the increase in the density.

Figure 5 shows the removal rate as a function of the oxygen additive amount using different filament materials. In this figure, the plots of $\mathrm{W}$ filament are our previous study $[17,18]$. The hydrogen flow rate was fixed at $100 \mathrm{sccm}$ 


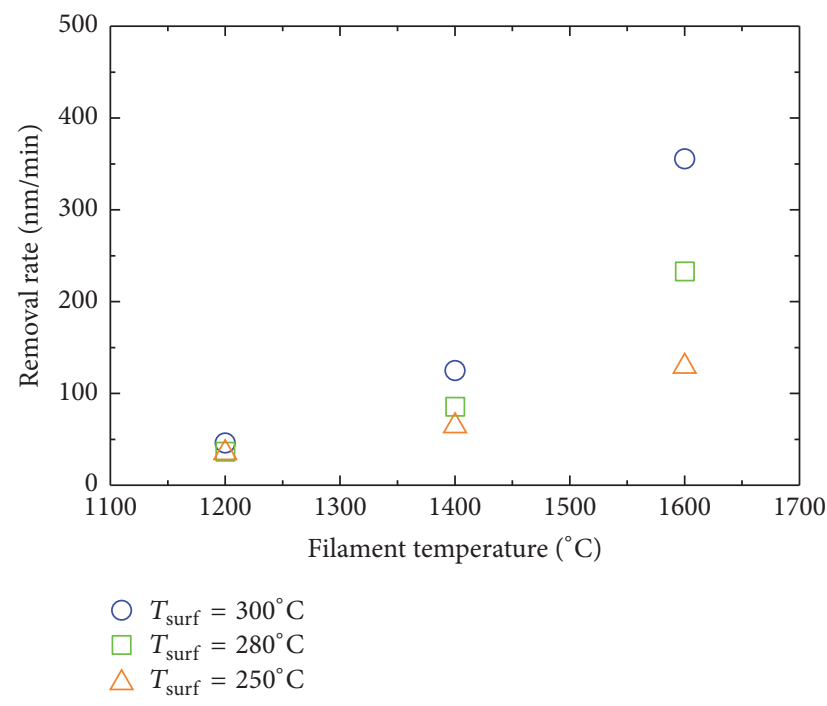

FIGURE 4: The removal rate as a function of the filament temperature when the surface temperatures were 250,280 , and $300^{\circ} \mathrm{C}$, respectively.

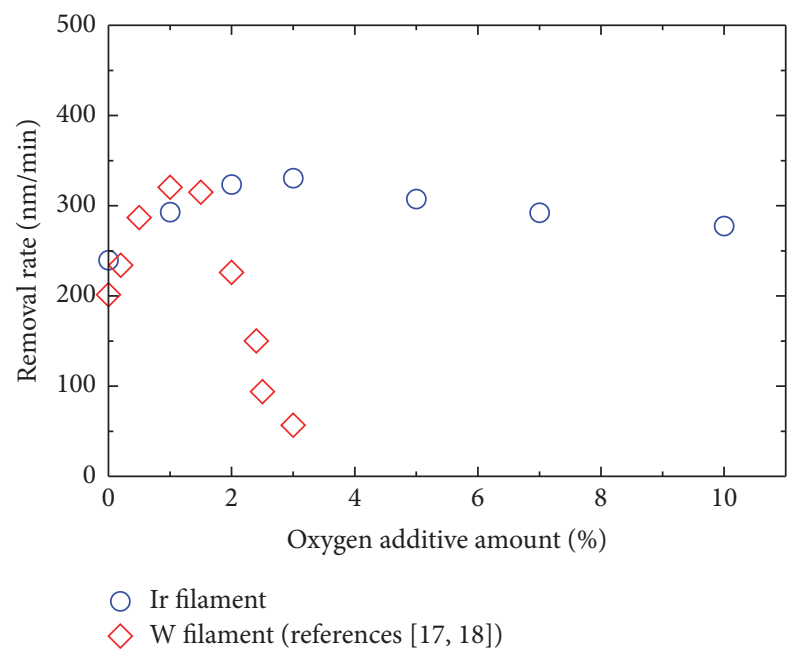

FIGURE 5: The removal rate as a function of the oxygen additive amount using different filament materials. The filament temperature was $1600^{\circ} \mathrm{C}$ and the surface temperature was $280^{\circ} \mathrm{C}$.

and the total pressure was $20 \mathrm{~Pa}$. Here, an oxygen additive amount is defined as the ratio of the flow rate of oxygen to hydrogen. The amount of $1.0 \%$ corresponds to an oxygen flow rate of $1.0 \mathrm{sccm}$. When using $\mathrm{W}$ filament, the removal rate increased with the oxygen additive amount up to $1.0 \%$ and then decreased rapidly. The removal rate was less than that in the pure hydrogen system at exceeding $2.0 \%$. When using Ir filament, the removal rate increased with the oxygen additive amount up to $2.0-3.0 \%$ and then decreased gradually. Besides, the removal rate was larger than that in the pure hydrogen system at $10.0 \%$ of the amount. Iridium is more resistant to oxidation than tungsten [21]. Therefore, the reason why the larger removal rate was stably obtained even under the oxygen additive amount higher than $2.0 \%$ may be ascribed to excellent oxidation resistivity of Ir metal. In the following, we will discuss the reason of the increase and the decrease in removal rate.

The increase in the removal rate is presumably ascribed to $\mathrm{OH}$ radicals because $\mathrm{OH}$ radicals must be more important than $\mathrm{O}$ radicals in the photoresist removal $[17,22,23]$. The decrease is explained by the decrease in the production rate of $\mathrm{H}$ radicals caused by the poisoning of oxygen [20]. However, according to Umemoto et al., when using Ir filament, there is no decrease of the $\mathrm{H}$ radical population with increase of oxygen additive amount [19]. Additionally, $\mathrm{OH}$ radical density increases with increase of the amount. $\mathrm{H}$ radicals might be disturbed by $\mathrm{OH}$ radicals when $\mathrm{H}$ radicals attack the photoresists because the radius of $\mathrm{OH}$ radical is bigger than that of $\mathrm{H}$ radical.

\section{Conclusions}

An environmentally friendly photoresist removal method is presented, in which $\mathrm{H}$ radicals produced from hydrogen gas on a hot iridium catalyst are used.

We clarified details of the relationship between the removal rate and surface temperature using thin film interference. This study may be able to provide one of analytical techniques to understand mechanism of decomposition reaction at interface between radicals and polymer from the aspect of kinetics.

We examined the removal properties using $\mathrm{H}$ radicals produced by the Ir catalyst and the oxygen addition effects on the removal rate. The photoresist removal rate increased with the oxygen additive amount and then decreased more gradually than in the case of using $\mathrm{W}$ filament. A number of $\mathrm{OH}$ radicals with high reactivity can be produced without decreasing $\mathrm{H}$ radicals when mixtures of hydrogen and oxygen are activated by Ir catalyst.

\section{Conflicts of Interest}

The authors declare that they have no conflicts of interest.

\section{Acknowledgments}

This study was financially supported by the Sanyo Broadcasting Foundation and JSPS KAKENHI Grant no. JP16K00992.

\section{References}

[1] H. Morinaga, T. Futatsuki, T. Ohmi, E. Fuchita, M. Oda, and C. Hayashi, "Behavior of ultrafine metallic particles on silicon wafer surface," Journal of The Electrochemical Society, vol. 142, p. 966, 1995.

[2] K. Hirose, H. Shimada, S. Shimomura, M. Onodera, and T. Ohmi, "Ion-Implanted Photoresist and Damage-Free Stripping," Journal of the Electrochemical Society, vol. 141, no. 1, pp. 192-205, 1994.

[3] H. Horibe, T. Kamimura, and K. Yoshida, "Removal of positivetone diazonaphthoquinone/novolak resist using UV laser irradiation," Journal of Photopolymer Science and Technology, vol. 18, no. 2, pp. 181-185, 2005. 
[4] M. A. Worsley, S. F. Bent, N. C. Fuller, and T. Dalton, "Characterization of neutral species densities in dual frequency capacitively coupled photoresist ash plasmas by optical emission actinometry," Journal of Applied Physics, vol. 100, no. 8, p. 083301, 2006.

[5] K. Shinagawa, H. Shindo, K. Kusaba, T. Koromogawa, J. Yamamoto, and M. Furukawa, "Ashing properties in a surfacewave mode plasma with a high-permittivity alumina window," Japanese Journal of Applied Physics, vol. 40, no. Part 1, No. 10, pp. 5856-5860, 2001.

[6] S. Fujimura and H. Yano, "Heavy metal contamination from resists during plasma stripping," Journal of the Electrochemical Society, vol. 135, no. 5, pp. 1195-1201, 1988.

[7] K. Tsunokuni, K. Nojiri, S. Kuboshima, and K. Hirobe, "The effect of charge build-up on gate oxide breakdown during dry etching," in Proceedings of the 1987 Conference on Solid State Devices and Materials, Nippon Toshi Center, Tokyo, Japan, August 1987.

[8] A. Izumi and H. Matsumura, "Photoresist removal using atomic hydrogen generated by heated catalyzer," Japanese Journal of Applied Physics, vol. 41, no. Part 1, No. 7A, pp. 4639-4641, 2002.

[9] K. Hashimoto, A. Masuda, H. Matsumura, T. Ishibashi, and K. Takao, "Systematic study on photoresist removal using hydrogen atoms generated on heated catalyzer," Thin Solid Films, vol. 501, no. 1-2, pp. 326-328, 2006.

[10] M. Yamamoto, H. Horibe, H. Umemoto et al., "Photoresist removal using atomic hydrogen generated by hot-wire catalyzer and effects on Si-wafer surface," Japanese Journal of Applied Physics, vol. 48, no. 2, Article ID 026503, 2009.

[11] M. Yamamoto, T. Maruoka, A. Kono, H. Horibe, and H. Umemoto, "Order of reaction between photoresist and atomic hydrogen generated by a tungsten hot-wire catalyst," Applied Physics Express, vol. 3, no. 2, Article ID 026501, 2010.

[12] M. Yamamoto, T. Maruoka, Y. Goto et al., "Removal of ionimplanted photoresists using atomic hydrogen," Journal of the Electrochemical Society, vol. 157, no. 3, pp. H361-H370, 2010.

[13] M. Yamamoto, H. Umemoto, K. Ohdaira et al., "Enhancement of photoresist removal rate by using atomic hydrogen generated under low-pressure conditions," Journal of Photopolymer Science and Technology, vol. 28, no. 2, pp. 303-306, 2015.

[14] T. W. Hickmott, "Interaction of hydrogen with tungsten," The Journal of Chemical Physics, vol. 32, no. 3, pp. 810-823, 1960.

[15] J. N. Smith Jr. and W. L. Fite, "Reflection and dissociation of $\mathrm{H}_{2}$ on tungsten," The Journal of Chemical Physics, vol. 37, no. 4, pp. 898-904, 1962.

[16] H. Umemoto, "Production and detection of $\mathrm{H}$ atoms and vibrationally excited $\mathrm{H}_{2}$ molecules in CVD processes," Chemical Vapor Deposition, vol. 16, no. 10-12, pp. 275-290, 2010.

[17] M. Yamamoto, H. Umemoto, K. Ohdaira, T. Shikama, T. Nishiyama, and H. Horibe, "Oxygen additive amount dependence of rate of photoresist removal by $\mathrm{H}$ radicals generated on a tungsten hot-wire catalyst," Japanese Journal of Applied Physics, vol. 55, no. 7, Article ID 076503, 2016.

[18] M. Yamamoto, K. Maejima, H. Umemoto et al., "Enhancement of removal uniformity by oxygen addition for photoresist removal using $\mathrm{H}$ radicals generated on a tungsten hot-wire catalyst," Journal of Photopolymer Science and Technology, vol. 29, no. 4, pp. 639-642, 2016.

[19] H. Umemoto, H. Kusanagi, K. Nishimura, and M. Ushijima, "Detection of radical species produced by catalytic decomposition of $\mathrm{H}_{2}, \mathrm{O}_{2}$ and their mixtures on heated Ir surfaces," Thin Solid Films, vol. 517, no. 12, pp. 3446-3448, 2009.
[20] H. Umemoto and M. Moridera, "Production and detection of reducing and oxidizing radicals in the catalytic decomposition of $\mathrm{H}_{2} / \mathrm{O}_{2}$ mixtures on heated tungsten surfaces," Journal of Applied Physics, vol. 103, no. 3, p. 034905, 2008.

[21] J. F. Mulson and E. W. Müller, "Corrosion of tungsten and iridium by field desorption of nitrogen and carbon monoxide," The Journal of Chemical Physics, vol. 38, no. 11, pp. 2615-2619, 1963.

[22] S. Fujimura, K. Shinagawa, M. T. Suzuki, and M. Nakamura, "Resist stripping in an $\mathrm{O}_{2}+\mathrm{H}_{2} \mathrm{O}$ plasma downstream," Journal of Vacuum Science and Technology B, vol. 9, article 357, 1991.

[23] H. Sugimitsu, Basis and Application of Ozone, Tokyo, Japan, Korin, 1996 (Japanese). 

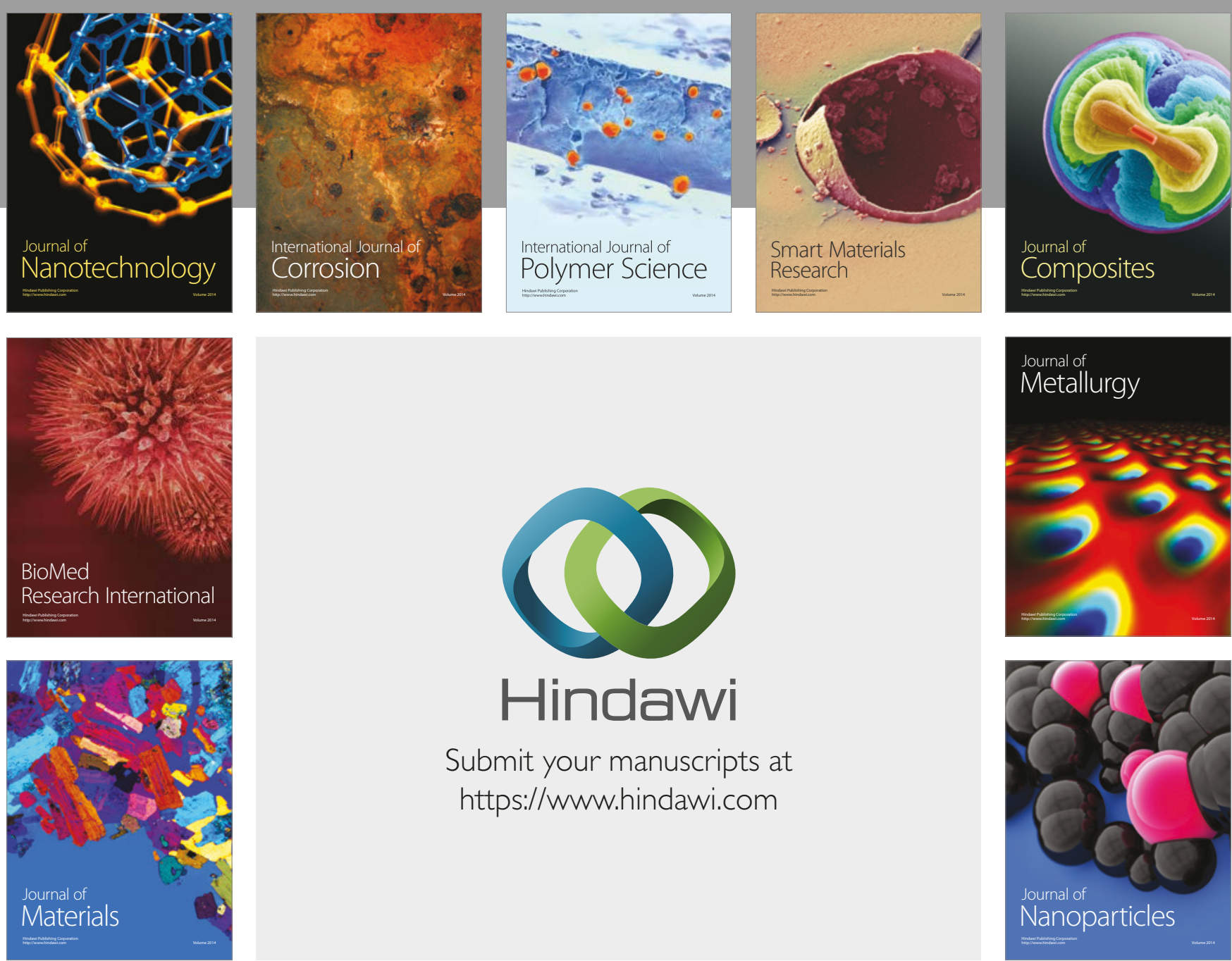

\section{Hindawi}

Submit your manuscripts at

https://www.hindawi.com
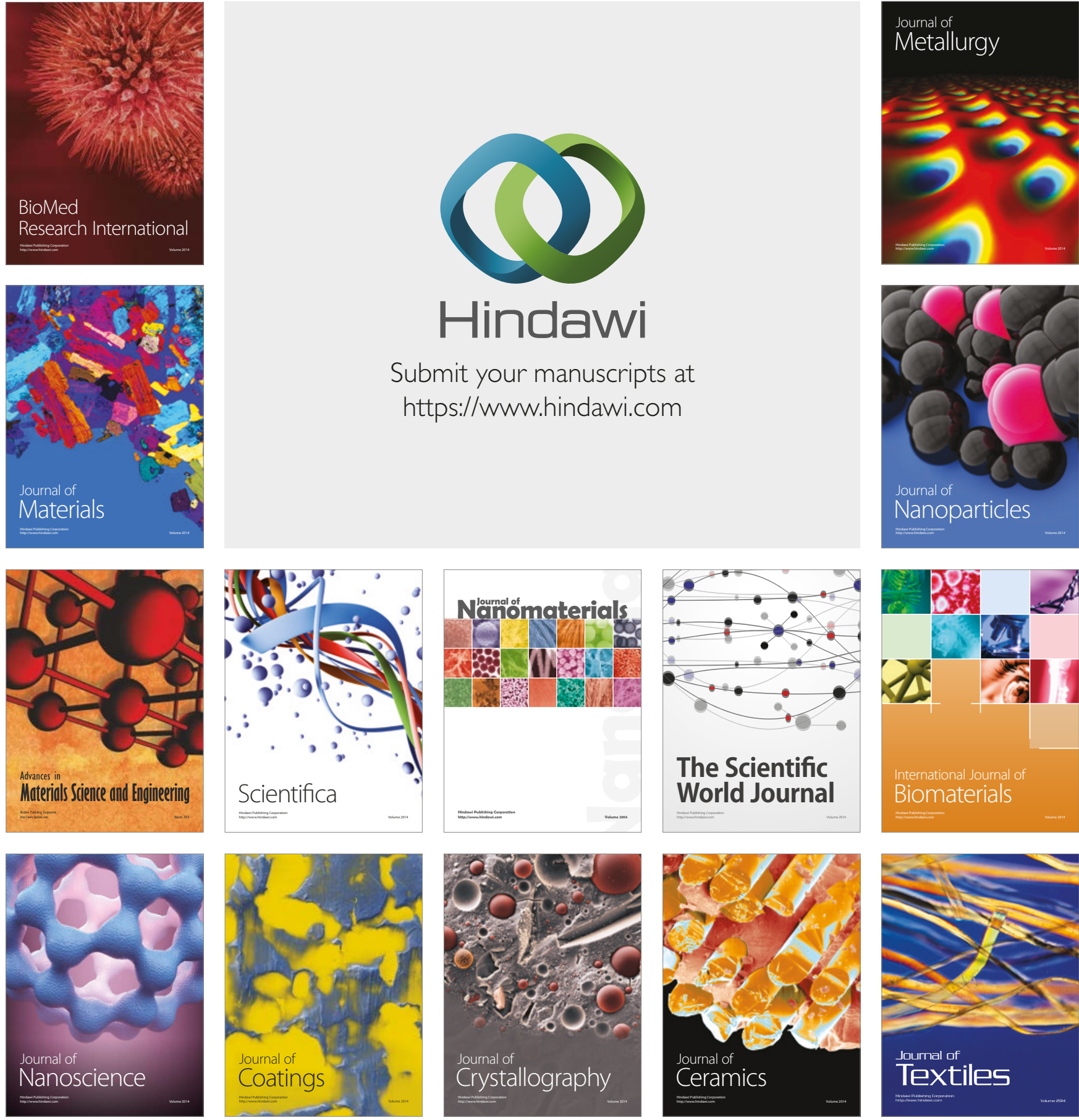

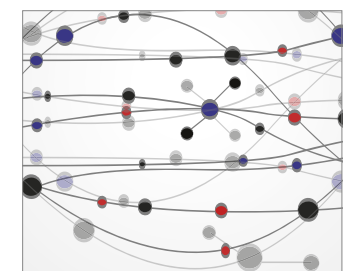

The Scientific World Journal
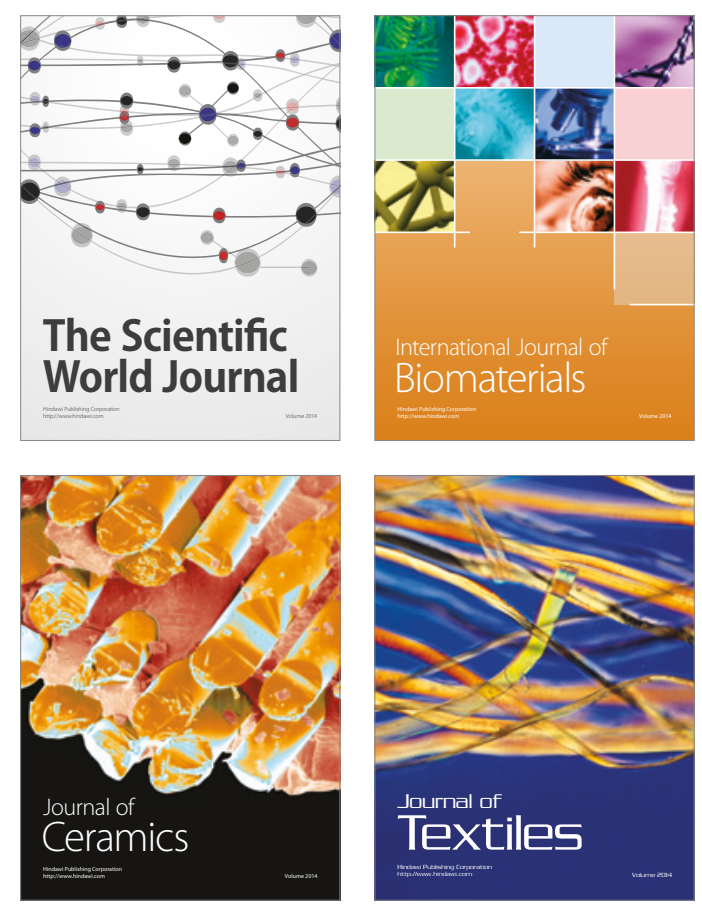